\title{
A cross-sectional survey of the pharmacy workforce in general practice in Scotland.
}

STEWART, D., MACLURE, K., NEWHAM, R., GIBSON-SMITH, K., BRUCE, R., CUNNINGHAM, S., MACLURE, A., FRY, S., MACKERROW, J., BENNIE, M.

This is a pre-copyedited, author-produced version of an article accepted for publication in Family Practice following peer review. The version of record STEWART, D., MACLURE, K., NEWHAM, R., GIBSON-SMITH, K., BRUCE, R., CUNNINGHAM, S., MACLURE, A., FRY, S., MACKERROW, J. and BENNIE, M. 2020. A cross-

sectional survey of the pharmacy workforce in general practice in Scotland. Family practice [online], 37(2), pages 206-212 is available online at: https://doi.org/10.1093/fampra/cmz052. 
Running title Pharmacy workforce in general practice in Scotland

Article category Health services research

\section{Authors}

Derek Stewart ${ }^{1}$, Katie MacLure ${ }^{1}$, Rosemary Newham² ${ }^{2}$ Kathrine Gibson-Smith ${ }^{1}$, Rachel Bruce $^{2,3}$, Scott Cunningham ${ }^{1}$, Andrew MacLure ${ }^{1}$, Sarah Fry ${ }^{4}$, James MacKerrow ${ }^{4}$, Marion Bennie ${ }^{2,4}$

\section{Affiliations}

${ }^{1}$ School of Pharmacy and Life Sciences, Robert Gordon University, Aberdeen, UK

${ }^{2}$ Strathclyde Institute of Pharmacy and Biomedical Sciences, University of Strathclyde, Glasgow, UK

${ }^{3}$ Pharmacy Services, Glasgow NHS Greater Glasgow and Clyde

${ }^{4}$ Public Health and Intelligence, NHS National Services Scotland, Edinburgh, UK

\section{Corresponding author Professor Derek Stewart}

\section{Key messages}

- There is a lack of capacity within the general practice workforce

- The pharmacy team is highly qualified and experienced

- Pharmacy team members deliver an array of patient care activities

- There are high levels of confidence, competence and integration 
Abstract

\section{Background}

In Scotland, there has been significant investment in pharmacy teams in general medical practices over recent years, aligned to current government policy.

\section{Objectives}

To characterise the national pharmacy workforce including activities undertaken, perceived competence and confidence, as well as perception of integration of the intervention.

\section{Method}

A cross-sectional survey of all pharmacists and pharmacy technicians in general practices. Survey items were: demographics, activities undertaken and experiences. The NoMAD tool (Improving the Normalization of Complex Interventions) was included as a measure of perspectives of implementation. Post-piloting, a questionnaire link was sent to all pharmacists $(n=471)$ and pharmacy technicians $(n=112)$. A total NoMAD score was obtained by assigning 1 (strongly disagree) to 5 (strongly agree) to each item.

\section{Results}

Responses were received from 393 (83.4\%) pharmacists and 101 (91.8\%) pharmacy technicians. Three quarters of pharmacists (74.6\%) and pharmacy technicians (73.3\%) had been qualified for over ten years. Two thirds of pharmacists $(68.4 \%)$ were 
independent prescribers, with three quarters (72.3\%) currently prescribing. Respondents worked in a median of two practices and were providing a range of activities including medication/polypharmacy reviews, medicines reconciliation, prescribing efficiencies and training. Respondents reported high levels of competence and confidence (median 8, scale 0-10 highest). Median NoMAD total score (scale 20-100 highest, Cronbach's alpha 0.89 ) was 80 for pharmacists and 75 for pharmacy technicians, $p \leq 0.001$.

\section{Conclusion}

The general practice pharmacy workforce in Scotland is experienced, well-qualified and integrated within general practices, delivering a range of activities. These findings have implications for workforce planning and future education and training.

\section{Keywords}

evaluation studies, general practice, multimorbidity, pharmacy, Scotland, surveys and questionnaires 


\section{Introduction}

Globally, public health systems are coming under increasing pressures due to complex and inter-related factors, including the lack of capacity within the general medical practice workforce. ${ }^{1-3}$ Additionally, the growing prevalence of multimorbidity and the associated increase in medicines use and healthcare appointments has led to an overwhelming burden. ${ }^{4,5}$ Accordingly, the need to better integrate and transform health and social care services, building broader multidisciplinary teams is well-known. ${ }^{6}$

There is a growing evidence base detailing pharmacists' contributions to patient care within general medical practices. Systematic reviews of pharmacist services (largely medication review) provide robust evidence of effectiveness on endpoints of medicines use and clinical outcomes. ${ }^{7,8}$ The degree of integration within general practice is a factor in service provision quality with 'full integration' (i.e. permanent position, access to clinical information systems, level of clinical care, providing staff education, etc.) leading to improved health outcomes. ${ }^{8}$ Gaining the trust of patients and the multidisciplinary team is fundamental, as is a flexible delivery model responsive to practice and patient needs. ${ }^{9}$ Being able to prescribe medicines and manage ongoing care is also likely to bring further benefits of including reduced workload for others. ${ }^{10,11}$ Pharmacist prescribing was introduced to the United Kingdom (UK) in 2003 (supplementary prescribing) and 2006 (independent prescribing). ${ }^{11}$ Implementation is advanced in Scotland where, in 2017 , approximately $40 \%$ of pharmacists were registered prescribers or undertaking training. ${ }^{12}$ Systematic reviews have demonstrated effectiveness and safety of pharmacist prescribing in acute and chronic conditions, ${ }^{13}$ and the positive experiences of stakeholders. ${ }^{14}$

In England in 2016 pilot funding was allocated to employ 470 whole time equivalent (wte) pharmacists. ${ }^{15,16}$ Further investment is planned, with an aim for over 2,000 wte pharmacists in practices by 2020; a ratio of one pharmacist per 30,000 patients. ${ }^{18}$ Evaluation of the pilot has been positive, resulting in a significant contribution to patient safety, prescribing, and improved medicines knowledge of the wider clinical team. ${ }^{18}$ 
Several other small studies have highlighted pharmacist's positive perceptions of their roles, ${ }^{19}$ activity, ${ }^{20}$ integration, ${ }^{21}$ and released general practitioner capacity. ${ }^{22}$

Pharmacists and pharmacy technicians in Scotland have been working in general practices for over three decades. In the UK, pharmacy technicians, like pharmacists, are regulated by the General Pharmaceutical Council. Training involves two years consecutive work-based experience under the direction of a pharmacist to whom the trainee is directly accountable for not less than 14 hours per week. The most significant investment to develop the general practice pharmacy workforce in Scotland was in 2015, with plans to recruit 140 wte additional pharmacists over three years. However, as the service evolved the need for a more flexible skill mix model became apparent and pharmacists as well as pharmacy technicians were appointed. ${ }^{23}$ This was augmented by further investment in $2018 / 19$, with the intention that every practice would have access to a pharmacist with advanced clinical skills by $2022 .{ }^{24}$ This paper reports the first study of a programme of evaluation (i.e. cross-sectional survey, workload modelling, in-depth case studies) aiming to characterise the national pharmacy workforce in Scottish general practices including activities undertaken, perceived competence and confidence, as well as perception of integration of the intervention. 


\section{Methods}

Design

The design was a cross-sectional survey using an online questionnaire.

Setting

Data collection took place from November 2017-January 2018 across general practice in Scotland.

Questionnaire development and testing

Questionnaire domains were: demographics; activities undertaken; and experiences (e.g. confidence, competence). The NoMAD tool (Improving the Normalization of Complex Interventions) was included as an objective measure of perspectives of implementation processes of pharmaceutical services delivered. Based on Normalization Process Theory, the 23 item tool was developed from constructs relating to implementation processes: identifying and understanding the ways that people make sense of the work of implementing and integrating; how they engage and enact; and evaluation. ${ }^{25,26}$ The questionnaire was reviewed for face and content validity by pharmacists, pharmacy technicians and experts in education and policy making, followed by 'Think Aloud' testing with five pharmacists and one pharmacy technician. ${ }^{27} \mathrm{~A}$ pilot was conducted with 24 pharmacists and 9 pharmacy technicians across Scotland.

\section{Recruitment and data collection}

All pharmacists and pharmacy technicians working in practices in Scotland were eligible for inclusion, with no exclusions. At survey launch, the link to the participant information leaflet and questionnaire was sent by email from contacts at each Scottish health board to all pharmacists $(n=471)$ and pharmacy technicians $(n=112)$. Two reminder emails were sent at fortnightly intervals. Several evidence-based approaches to maximising response rates to online surveys were adopted. ${ }^{28}$ Awareness raising initiatives included 
posting messages on social media and personal contact with Directors of Pharmacy in Scotland asking them to encourage participation.

\section{Analysis}

Data were analysed using SPSS (IBM SPSS Statistics for Windows, Version 21.0.). Participant wte was calculated from the number of hours respondents stated working in each practice. Correlation of scores of perceived competence and confidence were determined using Pearson product-moment statistic ( $p \leq 0.05$ significant). Internal consistency of NoMAD items was tested using Cronbach's alpha, aiming for $>0.60 .{ }^{29} \mathrm{~A}$ total NoMAD score (median and interquartile range, IQR) was obtained by assigning scores of 1 (strongly disagree) to 5 (strongly agree) to each of the items. Differences in total scores between pharmacists and pharmacy technicians were tested using MannWhitney $U$ Test. Two researchers independently performed summative content analysis on responses to open questions (aspects of activities undertaken, perceived competence, confidence, integration and any other relevant issues). ${ }^{30}$

\section{Ethical approval}

A UK university ethics committee approved the study; as a service evaluation it was exempt from NHS ethical and management review. 


\section{Results}

Responses were received from 393 (83.4\%) pharmacists and 101 (91.8\%) pharmacy technicians, with wte calculated from respondent reported working hours suggesting that there were 202 wte pharmacists and 57wte pharmacy technicians. Three health boards had no pharmacy technicians; the ratio of pharmacists to pharmacy technicians in the others ranged from approximately $1.5: 1$ to $12.5: 1$. Respondent characteristics are given in Table 1. Almost three quarters of pharmacists and pharmacy technicians had been qualified for over ten years $(74.6 \% ; 73.3 \%)$. While over half of pharmacists $(54.5 \%)$ and two thirds of pharmacy technicians $(66.3 \%)$ had been working in practices for less than five years; around one quarter of pharmacists (26.2\%) and one eighth of pharmacy technicians $(13.9 \%)$ reported more than ten years. Most had worked in other settings, with around two-thirds of pharmacists (64.9\%) in hospital and almost all $(88.0 \%)$ in community pharmacy. Three-quarters of pharmacy technicians $(75.2 \%)$ had worked in hospital and just under two-thirds (64.4\%) in community pharmacy.

Two thirds of pharmacists $(65.2 \%)$ had postgraduate qualifications, most commonly MSc Clinical Pharmacy (40.5\%). The majority of pharmacy technicians $(83.2 \%)$ had completed at least one post-qualification course. More than two thirds of pharmacists (68.4\%) were independent prescribers and one eighth (12.5\%) were undertaking training. Around one third of prescribers had been qualified for between one and five years $(37.2 \%)$, with one fifth $(21.5 \%)$ over ten years; three quarters of prescribers (72.3\%) were currently prescribing.

Respondents worked in a median of two practices (IQR pharmacists 2-5, range 1-29; IQR pharmacy technicians 3-5, range 1-54). In addition to working in practices, a quarter of pharmacists (25.2\%) and $14.9 \%$ of pharmacy technicians concurrently worked in hospital. Pharmacists and pharmacy technicians were providing a range of individual patient care activities (Table 2). A higher proportion of pharmacists than pharmacy technicians reported undertaking clinical activities: medication/polypharmacy reviews $(77.6 \% \vee 39.6 \%)$; medicines reconciliation (56.0\% $\vee 30.7 \%)$; hospital discharge 
letters $(53.7 \% \vee 23.8 \%)$; medicine safety reviews/recalls $(52.7 \% \vee 40.6 \%)$; and monitoring/reviewing high-risk medicines (52.4\% v 27.7\%).

The proportions of pharmacists and pharmacy technicians providing services at the practice population level were similar: prescribing efficiency work $(75.6 \%, \vee 79.2 \%)$; interpreting prescribing data based on the Prescribing Information System for Scotland (PRISMS) reports $(72.0 \% \vee 68.3 \%)$; providing staff training $(60.3 \% \vee 55.4 \%)$; audit/service improvement work (59.3\% v 57.4\%); and care home support (51.9\% v $49.5 \%)$.

Respondents reported high levels of competence and confidence for their 'day to day management skills', 'working with other members of the practice healthcare team' and 'dealing with patients' (median for all =8, scale was 0 -10 highest) (Table 3). Scores of perceived competence and confidence were highly correlated (all Pearson productmoment correlations, $\mathrm{p} \leq 0.001)$.

A total of 341 pharmacists and 80 pharmacy technicians completed the NoMAD component of the questionnaire. Of the 23 NoMAD items, the first three rated perceptions of familiarity and normality of practice working on a scale of $0-10$ (highest) while the remaining 20 items were grouped around the four NPT domains of: (i) coherence, (ii) cognitive participation, (iii) collective action and (iv) reflexive monitoring (5-point Likert scales). Median scores of 'how familiar does it feel?' for pharmacists and pharmacy technicians were 8 (IQR 5-10) and 7 (IQR 5-10) respectively. Median scores were the same for "feeling like a normal part of work" and higher scores for feeling that "it would become a normal part of work" (median 10, IQR 8-10; median 9, IQR 8-10). Responses to the remaining 20 items of the NoMAD measure are provided in Table 4. The scale had high internal consistency (Cronbach's alpha 0.89); scoring 5 for strongly agree to 1 for strongly disagree gave median total score of 80 (IQR 72-86) for pharmacists and 75 for pharmacy technicians (IQR 69-81) on a scale of 20-100 highest (midpoint 60). A Mann-Whitney U Test comparing the median total NoMAD scores of 
pharmacist and pharmacy technicians was significant $(p \leq 0.001)$ suggesting that pharmacists felt more positive about normalisation than pharmacy technicians. While responses from pharmacists and pharmacy technicians indicated agreement with positively worded statements, around half the pharmacists (55.4\%) and fewer pharmacy technicians (38.8\%) agreed that there was sufficient training. Responses were similar for resources being sufficient (pharmacists agreeing, 51.2\%; pharmacy technicians $45.0 \%$ ). Content analysis of the open comments identified several key issues. Respondents felt that they were making a positive contribution to patients' care,

"I find it very rewarding when you can improve a patient's understanding of medicines and stop or change medicines to improve their quality of life."

[pharmacist]

Many described positive experiences of integration,

"Working with other healthcare professionals in a multidisciplinary team, all helping towards patient health..."

[pharmacist]

Some were less positive, largely due to lack of awareness of the role and potential benefits.

"The role is constantly evolving, and I consider that patients and members of the GP team need further education about the beneficial role..." [pharmacist]

Working across several practices also hindered full integration,

"Working in different surgeries can be difficult to build a relationship... If you are in only 4 hours a week and working along the corridor in a GP/Nurse's room away from the main staff it can be difficult to put across who you are and what you are doing there." [pharmacy technician] 
While many expressed the need to adapt to a new setting and develop clinical skills, this appeared to be a particular issue for those transitioning from community pharmacy,

"Coming from community I needed to refresh my clinical knowledge that I have lost over the years. It's also a completely different job so getting to understand what to do and how to go about it can be difficult."

[pharmacist]

Workload and juggling competing tasks was an issue for some,

"Workload far exceeds time available. Difficult to prioritise tasks to work most efficiently for the benefit of the patients." [pharmacy technician] 


\section{Discussion}

Statement of key findings

Pharmacists and pharmacy technicians in Scottish general medical practices are highly qualified individuals with years of experience across several sectors, and many pharmacists prescribing independently. They are delivering an array of patient facing and practice population level activities, with high levels of confidence and perceived competence. Pharmacy technicians, in particular, commented that they require more training and resources to perform their roles.

\section{Strengths and limitations}

This study is timely given policy directions around pharmacist prescribing and general practice working. ${ }^{10,12-17,23,24}$ This is the first national survey to be published from any part of the UK describing in detail pharmacy team activities. Furthermore, the findings characterise pharmacists and pharmacy technicians, unlike other studies that have solely focused on pharmacists. The high response rates reduce potential for recruitment and response biases, increasing generalisability of the findings. A further strength is the novel use of a theoretical framework to study aspects of normalisation. However, the validity of self-reported data could not be confirmed and responses may be influenced by social desirability bias.

\section{Comparison with existing literature}

These findings add to the evidence base detailing pharmacy teams in general practice and reflect the results reported by others. ${ }^{18-22}$ Given that most studies to date have been conducted in a limited number of practices, ${ }^{19-22}$ potentially lacking generalisability, this study in Scotland provides a national perspective. Mann et al reported a survey of 159 pharmacists (response rate of $42 \%$ ) in England conducted in $2017 .{ }^{18}$ Most were undertaking patient-facing work focusing on medication reviews in those with long-term conditions, classifying this as a major part of their role. The majority had a positive 
outlook on their role in terms of working autonomously, innovatively and flexibly, and working closely with others.

While the practice setting in Scotland may be new for some, it is reassuring that the majority are highly experienced and well-qualified. Experiences from hospital and community are likely to translate well to general practice and may alleviate medicines related issues as patients transfer between care settings. ${ }^{32}$ Pharmacy teams in general practice may also provide opportunities for greater liaison with community pharmacy with likely positive consequences. There was variation in the ratio of pharmacists to pharmacy technicians across health boards and, while most respondents were working in two practices, this ranged up to 29 for pharmacists and 54 for pharmacy technicians. Having to work across many practices could potentially lead to a lack of continuity, thus hindering integration, as described by some respondents. There may be merit in standardising the allocation of pharmacy teams to practices based on objective measures of health board, practice and patient need. ${ }^{9}$ The 2018 General Medical Services Contract in Scotland describes priorities for service redesign over a three-year period. A three level pharmacotherapy service of 'core', 'additional advanced' and 'additional specialist' services is a priority area. ${ }^{32}$ Patient-facing and population services delivered by survey respondents align to all three levels, with pharmacist polypharmacy reviews categorised as 'additional specialist services'. Work is now underway in Scotland to scope and standardise activities at all three levels. Furthermore, there has been an expressed desire in Scotland to implement a five year Master of Pharmacy degree that fully integrates the pre-registration year. ${ }^{33}$ Part of this vision is to enhance further experiential learning and produce graduates that are clinically competent and able to meet the workforce requirements, especially in primary care.

Scottish Government ambitions for pharmacist prescribers was first articulated in $2013,{ }^{34}$ and reinforced in 2016. ${ }^{12}$ Many pharmacists in this study were practising independent prescribers, with the remainder either in, or about to commence, training. Clinical 
outcomes data from general practice would add to the published literature and support similar developments in other countries.

Respondents' activities suggest full integration into the practice team (i.e. level of patient care, accessing clinical information systems, education of other staff), thus potentially leading to improved patient outcomes. ${ }^{8}$ Further evidence of integration was apparent from responses to items of familiarity and normality of working, and the content analysis. The NOMAD tool has appropriate face and construct validity and internal consistency, ${ }^{25,26}$ and the high scores indicate successful implementation and embedding of new ways of working. The most negatively rated items were around pharmacy technicians' views on the availability and provision of sufficient training and resources, also identified from the comments. This, along with the allocation of pharmacists and pharmacy technicians to practices, may require attention to ensure that teams are fully integrated and services are maintained and sustainable.

\section{Implications for research}

Case studies of selected practices are underway, comprising quantitative and qualitative data collection, with key stakeholders. Further research should focus on quality of care and resultant outcomes.

\section{Conclusions}

This 2018 national survey of the pharmacy workforce in general practice in Scotland has characterised the pharmacists and pharmacy technicians appointed at this time as experienced, well-qualified and integrated within practices, delivering a range of patient facing and population-based activities. The new GMS contract in Scotland may require a wider skill mix of pharmacists and pharmacy technicians to deliver the tiered pharmacotherapy services which may have further implications for the workforce profile, workforce planning and future education and training requirements. 


\section{Ethical approval}

A UK university ethics committee approved the study; as a service evaluation it was exempt from NHS ethical and management review.

\section{Acknowledgements}

The authors acknowledge the contribution of all study respondents and those involved in questionnaire development.

\section{Funding}

This work was supported by the Scottish Government.

\section{Conflicts of interest}

There are no conflicts of interest to declare. 


\section{References}

1. OECD, 2012. Health at a Glance: Europe 2012. OECD Publishing. http://dx.doi.org/10.1787/9789264183896-en [accessed 20 May 2019].

2. World Health Organization. The World Health Report 2008. Primary Health Care - now more than ever. New York: The World Health Organization 2008. ISBN 978924156373 4.

3. Tinetti ME, Fried TR, Boyd CM. Designing health care for the most common chronic condition - multimorbidity. J Am Med Assoc. 2012;307(23):2493-94.

4. Barnett K, Mercer SW, Norbury M, Watt G, Wyke S, Guthrie B. Epidemiology of multimorbidity and implications for healthcare, research, and medical education: a cross sectional study. Lancet. 2012;380:37-43.

5. Van Den Bussche H, Schön G, Kolonko T, Hansen H, Wegscheider K, Glaeske G, Koller D. Patterns of ambulatory medical care utilisation in elderly patients with special reference to chronic diseases and multimorbidity - results from a claims data based observational study in Germany. BMC Geriatr. 2011;11:54.

6. Boyd C, Martin Fortin MD. Future of multimorbidity research: how should understanding of multimorbidity inform health system designs? Public Health Rev. 2010;32:451-74.

7. Tan EC, Stewart K, Elliott RA, George J. Pharmacist services provided in general practice clinics: a systematic review and meta-analysis. Res Social Adm Pharm. 2014;10(4):608-22.

8. Hazen AC, De Bont AA, Boelman L, Zwart DL, De Gier JJ, De Wit NJ, Bouvy ML. The degree of integration of non-dispensing pharmacists in primary care practice and the impact on health outcomes: A systematic review. Res Social Adm Pharm. $2018 ; 14(3): 228-40$.

9. Anderson C, Zhan K, Boyd M, Mann C. The role of pharmacists in general practice: a realist review. Res Social Adm Pharm, in press.

10. Stewart D, MacLure K, George J. Educating non medical prescribers. Br J Clin Pharmacol. 2012;74;662-7.

11. Stewart D, Jebara T, Cunningham S, Awaisu A, Pallivalapila A, MacLure K. Future perspectives on nonmedical prescribing. Ther Adv Drug Saf. 2017;8:183-97.

12. Scottish Government. Achieving Excellence in Pharmaceutical Care: A Strategy for Scotland. Edinburgh: The Scottish Government; 2017 http://www.gov.scot/Resource/0052/00523589.pdf [accessed 20 May 201].

13. Weeks G, George J, MacLure K, Stewart D. Non-medical prescribing versus medical prescribing for acute and chronic disease management in primary and secondary care (Review). Cochrane Database Syst Rev. 2016(11).

14. Jebara T, Cunningham S, MacLure K, Awaisu A, Pallivalapila A, Stewart D.

Stakeholders' views and experiences of pharmacist prescribing: a systematic review. Brit J Clin Pharmacol. 2018;84(9):1883-905.

15. Avery A. Pharmacists working in general practice: can they help tackle the current workload crisis? (editorial). Br J Gen Pract. 2017;67:390-1. 
16. NHS England. Building the Workforce-the New Deal for General Practice. Secondary Building the workforce: the new deal for general practice, 2015.

https://www.england.nhs.uk/commissioning/wp-

content/uploads/sites/12/2015/01/building-theworkforce-new-deal-gp.pdf [accessed 20 May 2019].

17. NHS England. General Practice Forward View, 2016.https://www.england.nhs.uk/publication/generalpractice-forward-view-gpfv/ [accessed 20 May 2019].

18. Mann C, Anderson C, Avery A, Waring J, Boyd MJ. Clinical pharmacists in general practice: pilot scheme. Independent evaluation report: full report, 2018.

https://www.nottingham.ac.uk/pharmacy/research/divisions/pharmacy-practice-andpolicy/research/cpigp.aspx pdf [accessed 20 May 2019].

19. Butterworth J, Sansom A, Sims L, Healey M, Kingsland E, Campbell J. Pharmacists' perceptions of their emerging general practice roles in UK primary care: a qualitative interview study. Br J Gen Pract. 2017;67(662):e650-8.

20. Bush J, Langley CA, Jenkins D, Johal J, Huckerby C. Clinical pharmacists in general practice: an initial evaluation of activity in one English primary care organisation. Int J Pharm Pract. 2018;26(6):501-6.

21. Bradley F, Seston E, Mannall C, Cutts C. Evolution of the general practice pharmacist's role in England: a longitudinal study. Br J Gen Pract. 2018;68(675):e72734.

22. Maskrey M, Johnson CF, Cormack J, Ryan M, Macdonald H. Releasing GP capacity with pharmacy prescribing support and New Ways of Working: a prospective observational cohort study. Br J Gen Pract. 2018;68(675):e735-42.

23. Scottish Government. Primary Care Funding Allocation for Pharmacists in GP Practices and Additional Prescription for Excellence Funding, 2015.

http://www.sehd.scot.nhs.uk/pca/PCA2015(P)16.pdf [accessed 20 May 2019].

24. Scottish Government. Primary Care Funding - Allocation for Pharmacists in GP Practices 2017-18, 2017. Available from:

http://www.sehd.scot.nhs.uk/pca/PCA2017(P)04.pdf [accessed 20 May 2019].

25. Rapley T, Girling M, Mair FS, Murray E, Treweek S, McColl E, Steen IN, May CR, Finch TL. Improving the normalization of complex interventions: part 1-development of the NoMAD instrument for assessing implementation work based on normalization process theory (NPT). BMC Med Res Methodol. 2018;18(1):133.

26. Finch TL, Girling M, May CR, Mair FS, Murray E, Treweek S, McColl E, Steen IN, Cook $C$, Vernazza CR, Mackintosh N. Improving the normalization of complex interventions: part 2-validation of the NoMAD instrument for assessing implementation work based on normalization process theory (NPT). BMC Med Res Methodol. 2018;18(1):135.

27. Van Oort L, Schröder C, French D. What do people think about when they answer the Brief Illness Perception Questionnaire? A 'think-aloud'study. $\mathrm{Br}$ J Health Psychol. 2011;16(2):231-45.

28. Sánchez-Fernández J, Muñoz-Leiva F, Montoro-Ríos FJ. Improving retention rate and response quality in Web-based surveys. Comput Human Behav. 2012;28(2):507-14.

29. DeVellis RF, 1991. Scale development: theory and applications. California: Sage Publications. ISBN 9781412980449. 
30. Elo, S., Kääriäinen, M., Kanste, O., Pölkki, T., Utriainen, K., Kyngäs, H. Qualitative content analysis: a focus on trustworthiness. Sage Open 2014:1-10.

31. Kwan JL, Lo L, Sampson M, Shojania KG. Medication reconciliation during transitions of care as a patient safety strategy: a systematic review. Ann Intern Med.

2013;158:397-403.

32. Scottish Government. The 2018 General Medical Services Contract in Scotland, 2017. https://www.gov.scot/publications/2018-gms-contract-scotland/ [accessed 20 May 2019].

33. Scottish Government. Five-year integrated initial education programme for pharmacists in Scotland: scoping report, 2017.

https://www2.gov.scot/Resource/0051/00517173.pdf [accessed 20 May 2019].

34. Scottish Government. Achieving Excellence in Pharmaceutical Care: A Strategy for Scotland. [online]. Edinburgh: The Scottish Government; 2017.

http://www.gov.scot/Resource/0052/00523589.pdf [accessed 20 May 2019]. 
Table 1. Self-reported demographics and characteristics of pharmacists and pharmacy technicians; data collected 2018

\begin{tabular}{|c|c|c|}
\hline & Pharmacists, \% (n) $(n=393)$ & $\begin{array}{l}\text { Pharmacy technicians, \% (n) } \\
(n=101)\end{array}$ \\
\hline \multicolumn{3}{|l|}{ Gender } \\
\hline Female & $82.7(325)$ & $90.1(91)$ \\
\hline Male & $15.5(61)$ & $9.9(10)$ \\
\hline Prefer not to say & $1.8(7)$ & 0 \\
\hline \multicolumn{3}{|l|}{ Age (years)* } \\
\hline$<30$ & $13.2(52)$ & $7.9(8)$ \\
\hline $30-39$ & $34.4(135)$ & $34.7(35)$ \\
\hline $40-49$ & $28.8(113)$ & $32.7(33)$ \\
\hline $50-59$ & $21.4(84)$ & $21.8(22)$ \\
\hline$\geq 60$ years & $2.0(8)$ & $3.0(3)$ \\
\hline \multicolumn{3}{|c|}{ Years qualified as pharmacist/pharmacy technician* } \\
\hline$<1$ & $0.3(1)$ & $2.0(2)$ \\
\hline $1-4$ & $9.9(39)$ & $10.9(11)$ \\
\hline $5-9$ & $15.3(60)$ & $11.9(12)$ \\
\hline $10-14$ & $16.3(64)$ & $30.7(31)$ \\
\hline $15-19$ & $16.5(65)$ & $7.9(8)$ \\
\hline$\geq 20$ & $41.7(164)$ & $34.7(35)$ \\
\hline \multicolumn{3}{|c|}{ Years working in GP practices } \\
\hline$<1$ & $20.1(79)$ & $20.8(21)$ \\
\hline $1-4$ & $34.4(135)$ & $45.5(46)$ \\
\hline $5-9$ & $15.8(62)$ & $19.8(20)$ \\
\hline $10-14$ & $12.2(48)$ & $12.9(13)$ \\
\hline$\geq 15$ & $14.0(55)$ & $1.0(1)$ \\
\hline \multicolumn{3}{|c|}{ Years of experience in hospital pharmacy } \\
\hline$<1$ & $6.4(25)$ & $2.0(2)$ \\
\hline $1-4$ & $20.1(79)$ & $17.8(18)$ \\
\hline $5-9$ & $14.5(57)$ & $21.8(22)$ \\
\hline $10-14$ & $6.6(26)$ & $11.9(12)$ \\
\hline$\geq 15$ & $4.8(19)$ & $21.8(22)$ \\
\hline \multicolumn{3}{|c|}{ Years of experience in community pharmacy } \\
\hline$<1$ & $6.1(24)$ & $8.9(9)$ \\
\hline $1-4$ & $20.1(79)$ & $16.8(17)$ \\
\hline $5-9$ & $21.4(84)$ & $14.9(15)$ \\
\hline $10-14$ & $17.8(70)$ & $5.0(5)$ \\
\hline$\geq 15$ & $22.6(89)$ & $18.8(19)$ \\
\hline \multicolumn{3}{|c|}{ Years of experience in other settings (e.g. care homes, prisons, academia) } \\
\hline$<1$ & $1.5(6)$ & $2.0(2)$ \\
\hline $1-4$ & $7.6(30)$ & $3.0(3)$ \\
\hline $5-9$ & $3.3(13)$ & $1.0(1)$ \\
\hline $10-14$ & $1.5(6)$ & $5.0(5)$ \\
\hline$\geq 15$ & $2.5(10)$ & 0 \\
\hline
\end{tabular}

* do not total $100 \%$ due to missing data 
Table 2. Self-reported individual patient care activities provided by pharmacists and pharmacy technicians; data collected 2018

\begin{tabular}{|c|c|c|}
\hline Activity & $\begin{array}{c}\text { Pharmacists, } \%(n) \\
(n=393)\end{array}$ & $\begin{array}{c}\text { Pharmacy } \\
\text { technicians, \% (n) } \\
(n=101)\end{array}$ \\
\hline Medication/polypharmacy reviews & $77.6(305)$ & $39.6(40)$ \\
\hline Medicines reconciliation & $56.0(220)$ & $30.7(31)$ \\
\hline Hospital discharge letters & $53.7(211)$ & $23.8(24)$ \\
\hline Medicine safety reviews/recalls & $52.7(207)$ & $40.6(41)$ \\
\hline Monitoring/reviewing high risk medicines & $52.4(206)$ & $27.7(28)$ \\
\hline Hospital outpatient requests & $46.6(183)$ & $13.9(14)$ \\
\hline Acute medication requests & $43.8(172)$ & $13.9(14)$ \\
\hline Chronic disease clinics (prescribing) & $29.8(117)$ & - \\
\hline Repeat medication requests & $28.8(113)$ & $13.9(14)$ \\
\hline Chronic disease clinics (non-prescribing) & $10.7(42)$ & - \\
\hline Management of minor ailments (prescribing) & $8.7(34)$ & - \\
\hline Management of minor ailments (non-prescribing) & $6.4(25)$ & - \\
\hline Acute/triage clinics (prescribing) & $5.9(23)$ & - \\
\hline Acute/triage clinics (non-prescribing) & $3.3(13)$ & - \\
\hline
\end{tabular}


Table 3. Pharmacist and pharmacy technician self-rated competence and confidence; data collected 2018

\begin{tabular}{|l|c|c|}
\hline Activity & $\begin{array}{c}\text { Pharmacists } \\
\text { (median, IQR) } \\
\text { (n=393) }\end{array}$ & $\begin{array}{c}\text { Pharmacy } \\
\text { technicians } \\
\text { (median, IQR) } \\
\text { (n=101) }\end{array}$ \\
\hline $\begin{array}{l}\text { How competent do you feel undertaking your } \\
\text { role in GP practice on a day to day basis? }\end{array}$ & $8(7-9)$ & $8(7-9)$ \\
\hline $\begin{array}{l}\text { How confident do you feel undertaking your role } \\
\text { in GP practice on a day to day basis? }\end{array}$ & $8(6-9)$ & $8(7-9)$ \\
\hline $\begin{array}{l}\text { How competent do you feel working with other } \\
\text { members of the GP practice healthcare team? }\end{array}$ & $8(7-9)$ & $8(7-9)$ \\
\hline $\begin{array}{l}\text { How confident do you feel working with other } \\
\text { members of the GP practice healthcare team? }\end{array}$ & $8(7-9)$ & $8(6-9)$ \\
\hline $\begin{array}{l}\text { How competent do you feel in dealing with } \\
\text { patients in GP practice? }\end{array}$ & $8(7-9)$ & $8(6-9)$ \\
\hline $\begin{array}{l}\text { How confident do you feel in dealing with } \\
\text { patients in GP practice? }\end{array}$ & $8(7-9)$ & $8(6-9)$ \\
\hline $\begin{array}{l}\text { How competent do you feel in your day to day } \\
\text { management skills within GP practice? }\end{array}$ & $8(6-9)$ & $8(7-9)$ \\
\hline $\begin{array}{l}\text { How confident do you feel in your day to day } \\
\text { management skills within GP practice? }\end{array}$ & $8(6-9)$ & $8(6.25-9)$ \\
\hline
\end{tabular}

Scale $0-10$, with 10 representing the highest level of confidence or competence 
Table 4. Pharmacist $(n=341)$ and pharmacy technician $(n=80)$ responses to four constructs and twenty items of the NOMAD measure; data collected 2018

\begin{tabular}{|c|c|c|c|c|c|c|}
\hline \multirow[b]{2}{*}{$\begin{array}{l}\text { Statement } \\
\text { (intervention refers to pharmacy team work in } \\
\text { general practice) }\end{array}$} & \multicolumn{3}{|c|}{ Pharmacist responses* } & \multicolumn{3}{|c|}{ Pharmacy technician responses* } \\
\hline & $\begin{array}{l}\text { Strongly } \\
\text { agree/ } \\
\text { agree } \\
\%(n)\end{array}$ & $\begin{array}{l}\text { Neither } \\
\text { agree nor } \\
\text { disagree } \\
\%(n)\end{array}$ & $\begin{array}{l}\text { Disagree/ } \\
\text { strongly } \\
\text { disagree } \\
\% \text { (n) }\end{array}$ & $\begin{array}{l}\text { Strongly } \\
\text { agree/ } \\
\text { agree } \\
\%(n)\end{array}$ & $\begin{array}{l}\text { Neither } \\
\text { agree nor } \\
\text { disagree } \\
\%(\mathbf{n})\end{array}$ & $\begin{array}{l}\text { Disagree/ } \\
\text { strongly } \\
\text { disagree } \\
\%(n)\end{array}$ \\
\hline \multicolumn{7}{|l|}{ Statements relating to NPT construct of 'coherence' } \\
\hline $\begin{array}{l}\text { I can see how the intervention differs from usual } \\
\text { ways of working }\end{array}$ & $75.7(258)$ & $15.8(54)$ & $7.0(24)$ & $72.5(58)$ & $20.0(16)$ & $6.3(5)$ \\
\hline $\begin{array}{l}\text { Staff in this organisation have a shared } \\
\text { understanding of the purpose of the intervention }\end{array}$ & $71.6(244)$ & $15.8(54)$ & $12.3(42)$ & $62.5(50)$ & $17.5(14)$ & $18.8(15)$ \\
\hline $\begin{array}{l}\text { I understand how the intervention affects the nature } \\
\text { of my own work }\end{array}$ & $88.9(303)$ & $9.1(31)$ & $0.9(3)$ & $87.5(70)$ & $8.8(7)$ & $2.5(2)$ \\
\hline $\begin{array}{l}\text { I can see the potential value of the intervention for } \\
\text { my work }\end{array}$ & $96.2(328)$ & $2.9(10)$ & $0.3(1)$ & $92.5(74)$ & $6.3(5)$ & $1.3(1)$ \\
\hline \multicolumn{7}{|l|}{ Statements of 'cognitive participation' } \\
\hline $\begin{array}{l}\text { There are key people who drive the intervention } \\
\text { forward and get others involved }\end{array}$ & $83.9(286)$ & $10.0(43)$ & $2.9(10)$ & $72.5(58)$ & $20.0(16)$ & $5.0(4)$ \\
\hline $\begin{array}{l}\text { I believe that participating in the intervention is a } \\
\text { legitimate part of my role }\end{array}$ & $97.1(331)$ & $2.3(8)$ & $0.3(1)$ & $91.3(73)$ & $5.0(4)$ & $2.5(2)$ \\
\hline $\begin{array}{l}\text { I'm open to working with colleagues in new ways to } \\
\text { use the intervention }\end{array}$ & $96.5(329)$ & $2.9(10)$ & $0.6(2)$ & $83.8(75)$ & $5.0(4)$ & $1.3(1)$ \\
\hline I will continue to support the intervention & $95.6(326)$ & $3.2(11)$ & $0.9(3)$ & $93.8(75)$ & $5.0(4)$ & $1.3(1)$ \\
\hline \multicolumn{7}{|l|}{ Statements relating to NPT construct of 'collective action' } \\
\hline $\begin{array}{l}\text { I can easily integrate the intervention into my } \\
\text { existing work }\end{array}$ & $76.0(259)$ & $10.3(35)$ & $11.1(38)$ & $82.5(66)$ & $10.0(8)$ & $7.5(6)$ \\
\hline +The intervention disrupts working relationships & $8.5(29)$ & $15.2(52)$ & $74.2(253)$ & $8.8(7)$ & $30.0(24)$ & $61.3(49)$ \\
\hline
\end{tabular}




\begin{tabular}{|c|c|c|c|c|c|c|}
\hline $\begin{array}{l}\text { I have confidence in other people's ability to use the } \\
\text { intervention }\end{array}$ & $71.3(243)$ & $22.0(75)$ & $4.1(14)$ & $68.8(55)$ & $27.5(22)$ & $3.8(3)$ \\
\hline $\begin{array}{l}\text { Work is assigned to those with skills appropriate to } \\
\text { the intervention }\end{array}$ & $71.3(243)$ & $19.6(67)$ & $6.7(23)$ & $60.0(48)$ & $27.5(22)$ & $12.5(10)$ \\
\hline $\begin{array}{l}\text { Sufficient training is provided to enable staff to } \\
\text { implement the intervention }\end{array}$ & $55.4(189)$ & $25.5(87)$ & $17.3(59)$ & $38.8(31)$ & $28.8(23)$ & $31.3(25)$ \\
\hline $\begin{array}{l}\text { Sufficient resources are available to support the } \\
\text { intervention }\end{array}$ & $51.2(177)$ & $25.8(88)$ & $21.1(72)$ & $45.0(36)$ & $23.8(19)$ & $31.3(25)$ \\
\hline Management adequately supports the intervention & $64.8(221)$ & $22.2(76)$ & $10.9(37)$ & $58.8(47)$ & $22.5(18)$ & $16.3(13)$ \\
\hline \multicolumn{7}{|c|}{ Statements relating to NPT construct of 'reflexive monitoring' } \\
\hline $\begin{array}{l}\text { I am aware of reports about the effects of the } \\
\text { intervention }\end{array}$ & $62.2(212)$ & $22.0(75)$ & $12.3(42)$ & $52.5(42)$ & $26.3(21)$ & $17.5(14)$ \\
\hline The staff agree that the intervention is worthwhile & $76.5(261)$ & $19.6(67)$ & $1.5(5)$ & $60.0(48)$ & $31.3(25)$ & $6.3(5)$ \\
\hline $\begin{array}{l}\text { I value the effects that the intervention has had on } \\
\text { my work }\end{array}$ & $83.0(283)$ & $12.6(43)$ & $1.5(5)$ & $73.8(59)$ & 23.8 (19) & $2.5(2)$ \\
\hline $\begin{array}{l}\text { Feedback about the intervention can be used to } \\
\text { improve it in the future }\end{array}$ & $89.1(304)$ & $7.0(24)$ & $0(0)$ & $88.8(71)$ & $10.0(8)$ & $1.3(1)$ \\
\hline I can modify how I work with the intervention & $83.9(286)$ & $9.7(33)$ & $0.6(2)$ & $73.8(59)$ & $20.0(16)$ & $5.0(4)$ \\
\hline
\end{tabular}

${ }^{+}$reverse scored; $*$ do not total $100 \%$ due to missing data 